\title{
ESTENOSIS LARINGOTRAQUEALES Resección y reconstrucción primaria
}

Juan Camilo Ramirez Rueda, MD. FRCSC *

\section{Resumen}

Se hace una revisión de los pacientes con estenosis que comprometen laringe y tráquea, tratados en el servicio de cirugía torácica del Hospital de San José con técnicas de resección y reconstrucción con anastomosis primaria, durante el período comprendido entre 1996 y 2005 . Se revisaron las historias clínicas y la información recolectada en forma retrospectiva se registró en un base de datos con: sexo, edad, procedencia, causa de la estenosis, localización, severidad, longitud, intervenciones previas relacionadas con el problema actual, antecedente de intubación, causa y duración de la misma, tiempo transcurrido entre la extubación y la aparición de la estenosis, estancia en UCI, antecedentes de traqueostomía, síntomas, manejo de la obstrucción aguda de la vía aérea, imágenes diagnósticas, hallazgos endoscópicos, procedimiento quirúrgico realizado, mortalidad, complicaciones, tiempo de hospitalización y resultados funcionales.

Se intervinieron 30 pacientes, 16 hombres y 14 mujeres. EI rango de edad varió entre 12 y 80 años, con un promedio de 44. Veintisiete pacientes tuvieron estenosis después de intubación ( 25 orotraqueal y 2 traqueostomía). Los síntomas de obstrucción se presentaron entre 30 y 90 días después del procedimiento y la duración osciló entre 3 y 45 días. En un paciente se diagnosticó una estenosis idiopática, en otro un seudotumor inflamatorio del cuerpo de la tráquea y en un tercero después de trauma por arma de fuego. En ocho la estrechez comprometió la región laringotraqueal, cuatro en el espacio subglótico y cuatro en el glótico en la comisura posterior. Siete de ellas secundarias a intubación orotraqueal y una idiopática. En 22 pacientes se localizó en el cuerpo de la tráquea. La longitud del segmento estrecho varió entre 2 y 6 cm. La severidad de la obstrucción osciló entre $70 \%$ y el $\mathbf{9 0 \%}$. En dos casos hubo combinación de estenosis y traqueomalacia. Los síntomas consistieron en disnea de esfuerzo y estridor laríngeo. Hubo obstrucción aguda de la vía aérea en 18 y fue tratada con traqueostomía en 16 y dilataciones en dos. Doce pacientes tenían cánula de traqueostomía cuando consultaron al hospital. Tres pacientes habían sido sometidos a diferentes procedimientos de resección y reconstrucción en otras instituciones. En todos los casos se realizó TAC de laringe y tráquea y fibrobroncoscopia. Tres traían resonancia nuclear magnética en el momento en que fueron evaluados por primera vez en nuestro servicio. Dos pacientes fueron valorados en otras instituciones con tomografía lineal. En 14 que presentaban cuadro clínico de obstrucción de la vía aérea se practicó una curva flujo volumen que mostró un patrón de obstrucción fija de la vía aérea superior. Fueron estudiados con gases arteriales que mostraron hipoxemia leve a severa en diez y retención de $\mathrm{CO}_{2}$ en cinco. Todos los pacientes se sometieron a resección y reconstrucción mediante anastomosis término-terminal de la vía aérea. En 26 se hizo abordaje cervical y cuatro requirieron uno combinado cervical y esternal.

En cuatro con estenosis subglóticas se realizaron resecciones de la placa anterior del cartílago y de la mucosa enferma, cobertura del defecto con un colgajo de tráquea membranosa y anastomosis entre el cartílago tiroides y la traquea. En uno se dejó una cánula de traqueostomía; en otro se colocó un tubo en $\mathbf{T}$ de silástico como molde, el cual se mantuvo durante siete meses. Los demás fueron extubados al terminar el procedimiento.

Cuatro pacientes que presentaron lesiones que comprometían la glotis requirieron reconstrucción compleja que consistió en una laringofisura y resección de toda la porción anterior del cartílago cricoides. En dos se dejó un tubo en T durante seis meses y en otro se colocó una cánula temporal de traqueostomía. Veintidós con estenosis del cuerpo de la tráquea fueron

Fecha recibido: marzo 15 de 2006

Fecha aceptado: abril 28 de 2006 
tratados con resección y anastomosis primaria de segmentos de tráquea cuya longitud varió entre los 3 y $6 \mathrm{~cm}$. Quince con resecciones mayores de $3 \mathrm{~cm}$ requirieron maniobras de liberación laríngea. Tres con estenosis mayores de $5 \mathrm{~cm}$ requirieron una esternotomía media para movilización del hilio pulmonar. En una paciente con estenosis y traqueomalacia causada por compresión por un bocio, el procedimiento se combinó con una tiroidectomía total. Una paciente presentó una nueva obstrucción después de la resección de una estenosis subglótica y fue reintervenida a los seis meses. El tiempo de hospitalización varió entre 8 y 20 días con un promedio de 9. Se produjeron dos muertes por fístulas traqueoinnominadas con hemorragia masiva y siete complicaciones en 30 procedimientos de resección y reconstrucción. Los resultados obtenidos en 26 pacientes fueron excelentes, con restablecimiento de la permeabilidad de la vía aérea y recuperación de la voz normal.

En la medida en que las técnicas de reconstrucción quirúrgicas se han perfeccionado y la experiencia con ellas es mayor, estamos cada vez más convencidos de que la resección y la reconstrucción temprana de estas lesiones se encuentra ampliamente justificada y que el tratamiento conservador no representa una alternativa apropiada.

Palabras clave: estenosis laringo-traqueal, cirugía del tórax, anastomosis de vía aérea, intubación, traqueostomía.

Abreviaturas: UCI, unidad de cuidados intensivos; TAC, tomografia axial computarizada.

\section{Introducción}

Las lesiones estenosantes de la región laríngea y traqueal adquieren gran importancia e interés en virtud de su complejidad, el riesgo de causar obstrucción aguda de la vía aérea que pone en peligro la vida del paciente y la posibilidad de comprometer estructuras y producir secuelas en relacionadas con la voz o la deglución, las cuales pueden estar relacionadas con la lesión misma o con los procedimientos utilizados para su tratamiento. De esta manera puede haber compromiso de las cuerdas vocales, los nervios laríngeos recurrentes y superiores, los grandes vasos del mediastino y del cuello, así como del esófago.

La estenosis de la vía aérea superior aparece en varias condiciones entre las cuales se destacan las inflamatorias, que pueden ser congénitas, infecciosas, idiopáticas y, con mayor frecuencia, secundarias a intubación traqueal con tubos oro o nasotraqueales y cánulas de traqueostomía, los tumores primarios (carcinomas, tumores mucoepidermoides, carcinoma adenoide quístico) o secundarios (carcinoma invasor del tiroides, metástasis) y las secuelas de trauma de la región laringotraqueal. Con alguna frecuencia se presenta obstrucción en zonas de malacia, cuando hay pérdida de la estructura cartilaginosa de la tráquea debida a compresión crónica, inflamación, infección o isquemia de la pared. También se ve en enfermedades menos comunes como amiloidosis, policondritis recidivante, mediastinitis fibrosante, traqueobroncopatía osteocondroplásica y granu- lomatosis de Wegener. ${ }^{1}$ Aquellas causadas por intubación y traqueostomía son las más frecuentes ${ }^{2}$ aún hoy día en que los balones de los tubos endotraqueales son de baja presión. Los mecanismos más comunes son:

1. Isquemia por presión del balón del tubo o de la cánula de traqueostomía que se localiza en el cuerpo de la tráquea. Su incidencia ha disminuido de manera importante con el uso de los balones de baja presión y la deflación intermitente del mismo.

2. Isquemia por compresión del tubo en el punto más estrecho de la vía aérea. El uso de aquellos de un calibre inadecuado y la manipulación poco cuidadosa de los brazos que sostienen los circuitos de los ventiladores, hacen que se produzca mayor compresión e isquemia de la pared de la vía aérea en su parte más estrecha, que es el espacio subglótico y la glotis. Estas son las más complejas.

3. Lesiones obstructivas causadas por flacidez de la pared de la tráquea, que pueden resultar por isquemia o compresión extrínseca de bocios y tumores de la glándula tiroides. En ocasiones se producen por intubación prolongada, como resultado de isquemia e infección.

4. Lesiones obstructivas producidas por granulomas, las cuales se localizan con mayor frecuencia en las cuerdas vocales, el estoma de la traqueostomía 
o la tráquea distal, en el sitio en que la punta del tubo o la cánula de traqueostomía tiene contacto con la pared.

5. Tabiques y membranas que se presentan con mayor frecuencia en el sitio del estoma de la traqueostomía y no comprometen todo el espesor de la pared de la tráquea.

La complejidad de las estenosis laringotraqueales depende del tipo de lesión, localización, extensión y severidad del compromiso de la luz de la vía aérea, factores que determinan la posibilidad de practicar un tratamiento adecuado, cuya efectividad depende de la obtención de un calibre apropiado y estable de la vía aérea, el restablecimiento de los mecanismos protectores contra la aspiración y la recuperación del aparato fonatorio. La localización es uno de los determinantes más importantes de la complejidad de la lesión. De acuerdo con ella, y para efectos de este estudio, las estenosis pueden clasificarse en laríngeas puras, laringotraqueales, que por lo general comprometen la región subglótica de la laringe y de la tráquea, y las del cuerpo de la tráquea propiamente dichas. En la medida en que la laringe se encuentra comprometida, el tratamiento es más complejo. En el presente estudio haremos referencia sólo a las estenosis laringotraqueales y las del cuerpo de la tráquea por encima de la carina.

Antes de 1960 sólo aparecían en la literatura publicaciones anecdóticas de resecciones de segmentos de tráquea con reconstrucción primaria mediante anastomosis términoterminal. Para esa época se pensaba que sólo era posible extirpar dos o hasta tres anillos y llevar a cabo una reconstrucción con anastomosis primaria. Con el advenimiento y desarrollo de la ventilación mecánica y el empleo de tubos endotraqueales con balón, se produjo un incremento significativo de las estenosis postintubación en los Estados Unidos y Europa. ${ }^{3,4}$ El tratamiento se convirtió en un poderoso estímulo para el desarrollo de nuevas técnicas de resección y reconstrucción. Hermes Grillo en 1970 describió técnicas de movilización de los aspectos anterolaterales de la tráquea y elevación de la carina mediante la liberación intrapericárdica del hilio pulmonar derecho. También destacó la importancia de la flexión del cuello para disminuir la tensión sobre la anastomosis traqueal. Utilizando estas maniobras de liberación fue posible resecar segmentos de cuatro a cinco centímetros de longitud y practicar una reconstrucción con anastomosis primaria ${ }^{5}$ La adición de la maniobras de liberación laríngea por Dedo y Fishman ${ }^{6}$ en 1969 y de liberación suprahioidea por Montgomery ${ }^{7}$ en 1974, hizo posible incrementar la longitud de las resecciones hasta el $50 \%$ de la longitud total de la tráquea. En 1964 Ogura y Powers publicaron la resección parcial del cricoides con anastomosis tirotraqueal ${ }^{8}$. Once años más tarde, en 1975 , Pearson describió una técnica para la resección de una anastomosis subglótica con preservación de la integridad de los nervios recurrentes, conservando la placa posterior del cartílago cricoides y llevando a cabo una reconstrucción con anastomosis tirotraqueal a menos de un centímetro de las cuerdas vocales 9 . Desde entonces, estas técnicas de resección y reconstrucción han venido siendo utilizadas en todo el mundo, cuyos resultados han sido objeto de numerosas publicaciones por parte de estos y otros autores..$^{9,10,11,12,13,14}$

En el presente estudio haremos una revisión de los pacientes con lesiones estenosantes que comprometen simultáneamente la laringe y la tráquea, tratados en el servicio de cirugía torácica del Hospital de San José con técnicas de resección y reconstrucción mediante anastomosis primaria, durante el período comprendido entre 1996 y 2005.

\section{Materiales y métodos}

Se revisaron las historias clínicas de los pacientes con diagnóstico de estenosis de la tráquea y de la región laringotraqueal intervenidos en el Hospital de San José, a quienes se les practicó resección y reconstrucción mediante anastomosis primaria de la vía aérea, durante el período comprendido entre enero de 1996 y abril de 2005. Los datos fueron recolectados en forma retrospectiva y registrados en una base de datos con la siguiente información: 
sexo, edad, procedencia, causa de la estenosis, localización, severidad de la obstrucción, longitud de la estenosis, intervenciones previas relacionadas con el problema actual, antecedente de intubación de la vía aérea, causa de la intubación, duración de la intubación, tiempo transcurrido entre la extubación y la aparición de la estenosis, estancia en la UCI, antecedente de traqueostomía para el manejo de la obstrucción de la vía aérea, síntomas, manejo de la obstrucción aguda de la vía aérea, imágenes diagnósticas, hallazgos endoscópicos, tipo de procedimiento quirúrgico practicado, mortalidad, complicaciones postoperatorias, tiempo de hospitalización y resultados funcionales.

\section{Técnicas de reconstrucción}

Independiente de la localización, todas las estenosis fueron tratadas mediante resección del segmento afectado con reconstrucción y anastomosis primaria, de acuerdo con las técnicas quirúrgicas descritas por Pearson, Grillo y otros. 5,9,10,11 La complejidad del procedimiento depende de la localización, la presencia y nivel de compromiso de la laringe y la longitud de la estenosis. Todas las técnicas de resección y reconstrucción primaria deben observar los siguientes principios:

1. Exposición quirúrgica amplia del segmento comprometido.

2. Anastomosis primaria libre de tensión con monofilamento absorbible.

3. Utilización de maniobras de liberación de la laringe y de la tráquea torácica, según el caso.

4. Mantenimiento de la disección lo más cerca posible de la pared traqueal para evitar la lesión de los nervios laríngeos recurrentes.

5. Aposición meticulosa de las mucosas de los dos segmentos, resección de todo el tejido enfermo y reconstrucción con mucosa sana.

\section{Estenosis del cuerpo de la tráquea}

Se definen como aquellas que se encuentran localizadas por debajo del cartílago cricoides y por encima de la carina. Se abordan inicialmente a través de una incisión cervical amplia en collar, con el paciente colocado en decúbito supino e hiperextensión del cuello con la cabeza en posición neutra, con el fin de exponer la mayor longitud posible de la tráquea. Se talla un colgajo superior hasta el hueso hioides y otro inferior hasta la horquilla del esternón. El abordaje de la tráquea cervical se realiza mediante retracción lateral de los músculos pretiroideos, exponiéndola en toda su longitud, incluyendo la laringe y seccionado el istmo de la glándula tiroides. De esta manera es posible realizar en este momento una evaluación inicial de la extensión del segmento enfermo. La disección debe mantenerse en un plano lo más cercano posible a la tráquea con el fin de evitar la lesión de los nervios laríngeos recurrentes, sin llevar a cabo ningún intento por identificarlos, excepto cuando se trata de tumores que pueden rechazarlos. La movilización de la tráquea se realiza mediante disección digital de la pared anterior hasta la carina evitando la de las paredes laterales para no disminuir la irrigación (Figura 1). Una vez se ha expuesto la tráquea y se ha realizado una evaluación preliminar de la longitud del segmento comprometido, se realiza la sección distal a la estenosis, procurando preservar los anillos sanos y se procede a obtener el control del segmento distal mediante la intubación del mismo con un tubo endotraqueal anillado que se conecta a un circuito de anestesia estéril (Figura 2). La resección del segmento enfermo se realiza en sentido cefálico, procurando, una vez más, mantener la disección en contacto con la pared traqueal y evitando el uso del electrocauterio. La sección proximal se lleva a cabo en el primer anillo que se observa sano (Figura 3). En este momento debe hacerse una evaluación cuidadosa del estado de la mucosa en los segmentos proximal y distal y extender la resección en caso necesario hasta encontrar mucosa totalmente sana. 


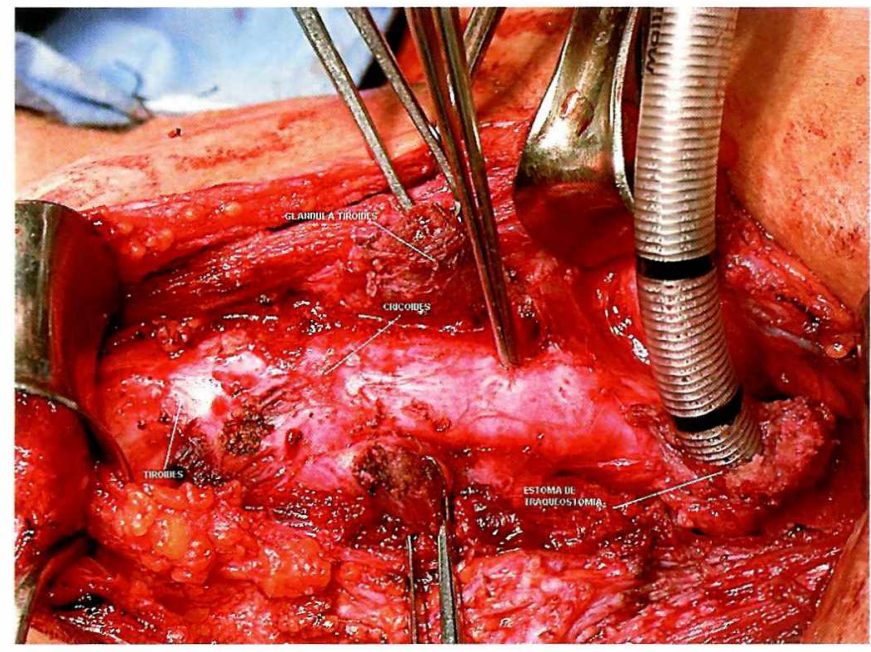

Figura I. Exposición de la tráquea cervical y la zona de estenosis.

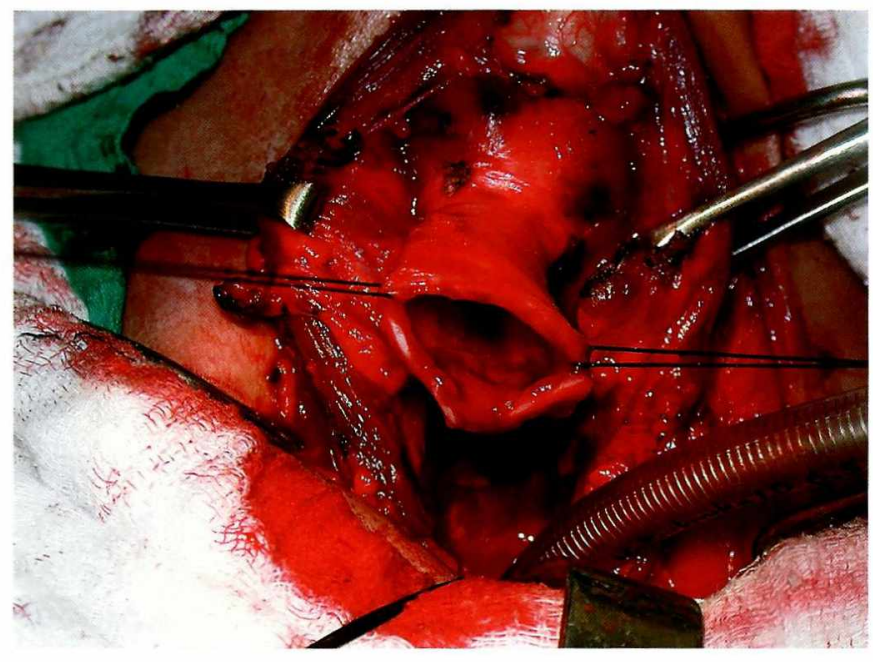

Figura 3. Disección proximal de la estenosis.

Cuando la longitud del segmento enfermo de tráquea es mayor de tres centímetros deben practicarse las maniobras de liberación de la laringe, supra o infrahioideas, descritas por Dedo y Fishman y Montgomery ${ }^{6,7}$ (Figura 4). La realización de estas maniobras permite obtener longitud adicional para realizar una anastomosis primaria libre de tensión. En nuestra serie hemos preferido realizar las maniobras de liberación suprahioidea, por considerar que producen poco compromiso de la deglución y un menor riesgo de lesionar la arteria laríngea superior. Si a pesar de estas medidas persiste la tensión al aproximar los dos segmentos y la longitud del segmento enfermo es

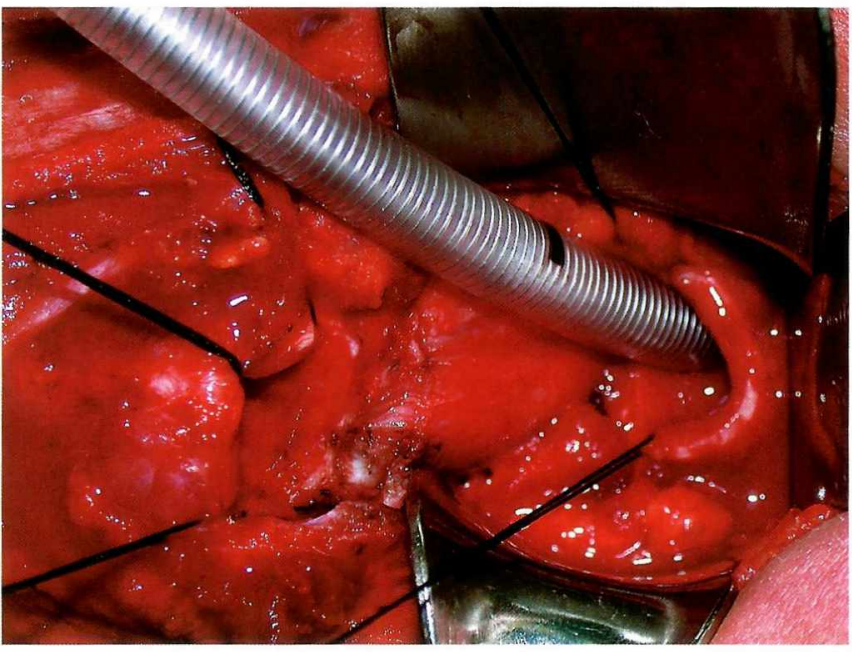

Figura 2. Intubación del segmento distal de la tráquea con un tubo anillado.
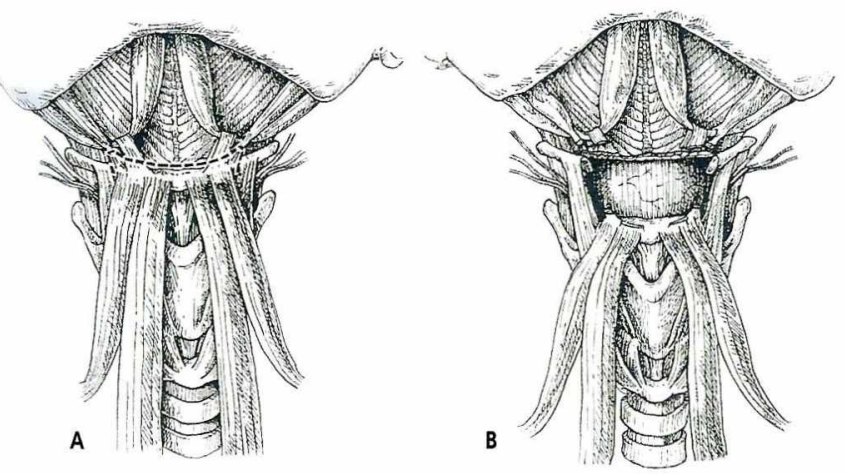

Figura 4. Maniobras de liberación laríngea supra e infrahioideas.

cercana al 50\% del total de la tráquea o la estenosis se localiza en el segmento distal, el abordaje cervical debe complementarse con una esternotomía media para acceder a la porción mediastínica de la tráquea y practicar maniobras de liberación de la misma, consistentes en la movilización de la carina y de los bronquios fuente a través del pericardio y del hilio pulmonar derecho, mediante sección del pericardio a su alrededor (Figura 5). Una vez verificada la ausencia de tensión al aproximar los dos segmentos, se realiza la anastomosis con puntos separados de monofilamento absorbible, colocados de manera que los nudos queden por fuera de la luz (Figuras 6 A y B). 

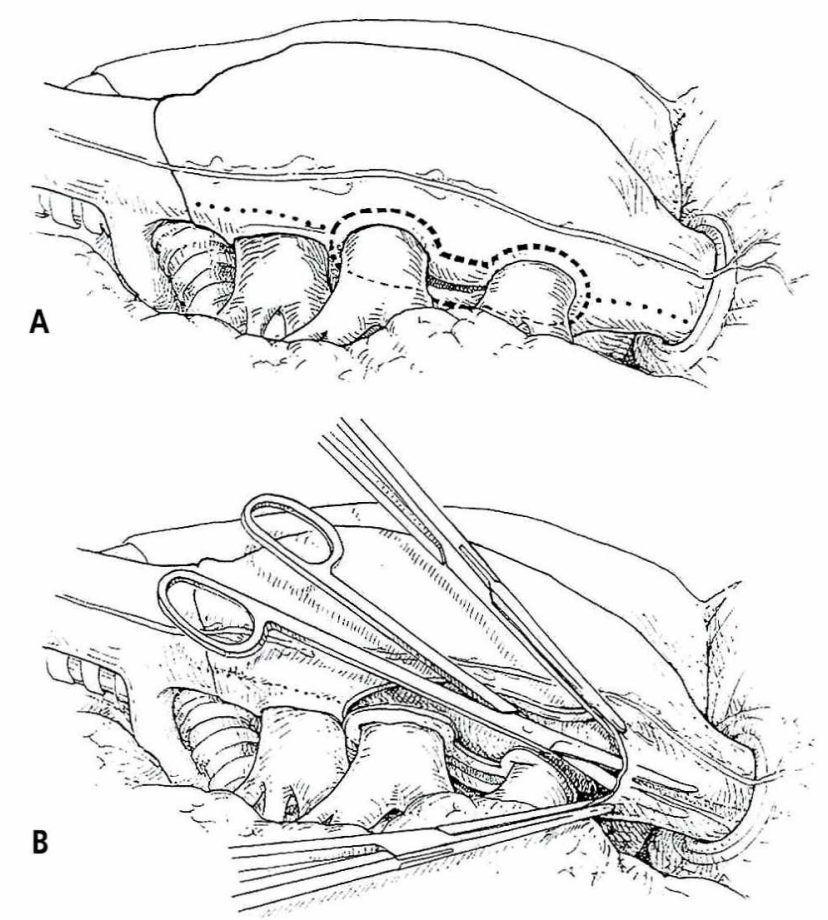

Figura 5. Maniobras de liberación de la tráquea y la carina en el mediastino.

En el momento de anudar las suturas debe colocarse el cuello en posición de flexión, que se mantiene por siete a ocho días mediante suturas que fijan el mentón a la pared anterior del tórax (Figura 7). El paciente, en lo posible, debe ser extubado al terminar el procedimiento. En estos casos no se requiere proteger la vía aérea con traqueostomía o algún tipo de soporte como los tubos de Montgomery.

En aquellos en quienes la longitud de la estenosis no permite una anastomosis libre de tensión después de haber realizado las maniobras descritas de liberación de la laringe, el abordaje cervical se complementa con el de la tráquea intratorácica a través de una esternotomía mediana, con el fin de realizar maniobras de liberación adicional de la tráquea, que consisten en la movilización del bronquio fuente derecho y el ascenso del hilio pulmonar derecho mediante la sección circular del pericardio alrededor del hilio. Con estas maniobras es posible obtener entre uno y dos centímetros adicionales de longitud.

En todos los casos operados, independiente de la longitud de la estenosis, la flexión del cuello del pa-

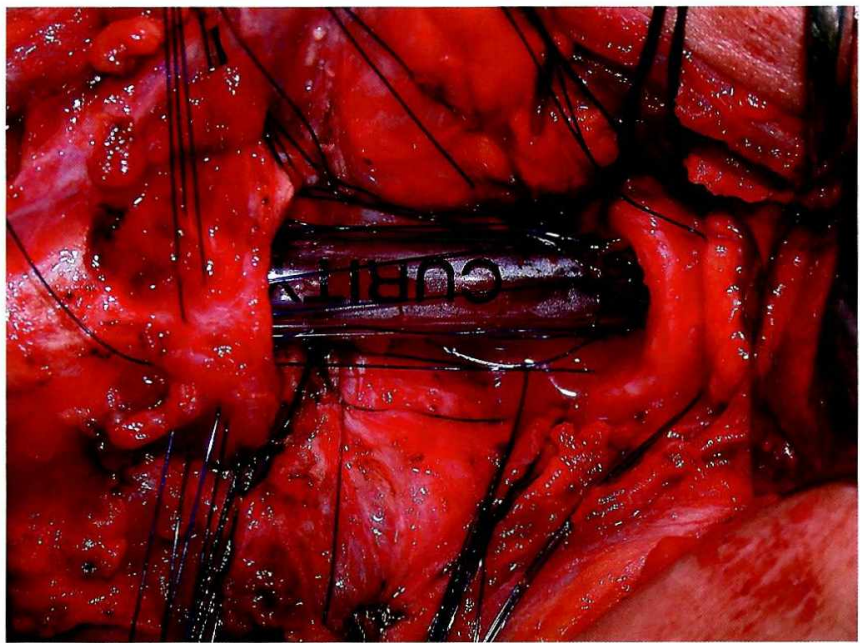

Figura 6A. Anastomosis terminoterminal entre los segmentos proximal y distal de la tráquea. Nótese que el tubo orotraqueal ha sido avanzado hacia el segmento distal antes de aproximar los dos segmentos y anudar las suturas.

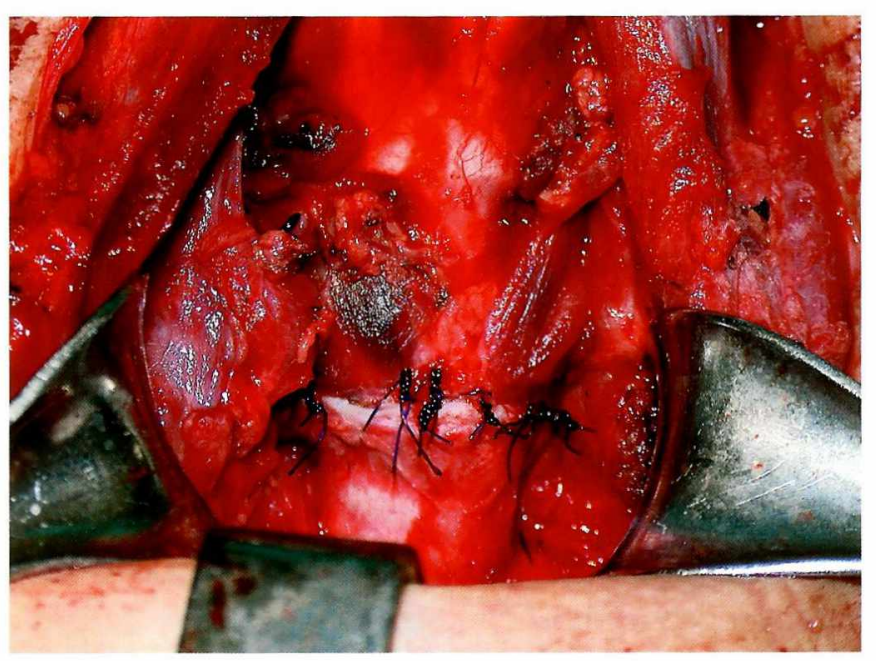

Figura 6B. Anastomosis terminada.

ciente se mantiene mediante la colocación de puntos de sutura no absorbible entre el mentón y la pared anterior del tórax.

\section{Estenosis laringotraqueales}

En esta localización se consideran tres tipos de estenosis que pueden comprometer en forma simultánea la laringe y la tráquea:

1. Lesiones que comprometen las dos estructuras por encima de la glotis (lesiones supraglóticas), que no analizaremos en este estudio. 


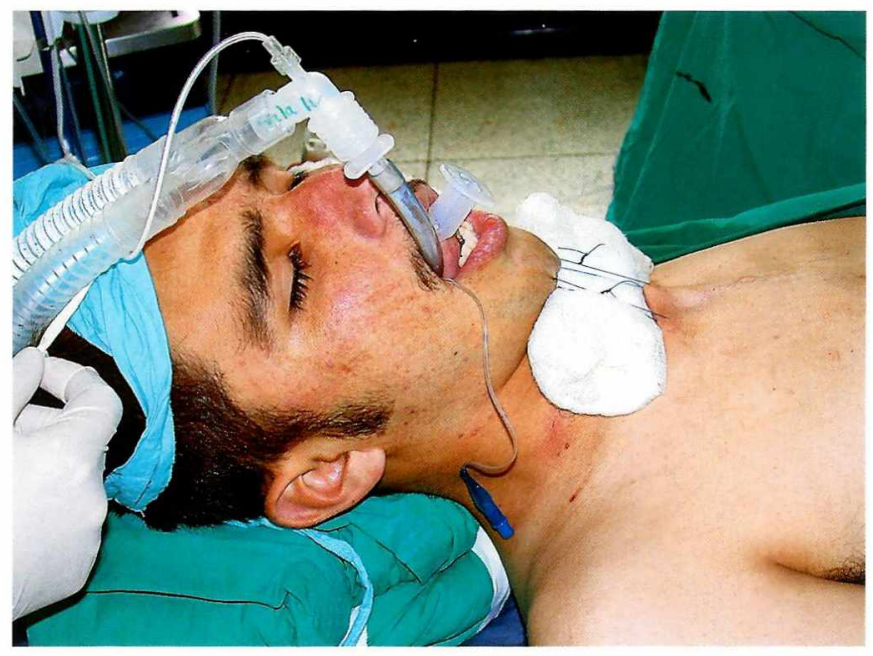

Figura 7. Puntos de flexión del cuello.

2. Lesiones que comprometen el espacio subglótico y la glotis, extendiéndose desde el primero hasta la comisura posterior de la glotis.

3. Estenosis subglóticas, que comprometen el espacio del mismo nombre que se encuentra entre las cuerdas vocales y el borde inferior del cartílago cricoides. Este espacio es crítico por ser la parte más estrecha de la vía aérea superior, muy vulnerable a las lesiones producidas por el tubo endotraqueal.

Para la resección y reconstrucción de este tipo de lesiones se aplican los mismos principios quirúrgicos descritos. Debido al compromiso de la laringe, revisten mayor complejidad debido a la extensión de la resección proximal y la dificultad de la reconstrucción. Cuando la estenosis compromete la laringe sólo en su porción subglótica, la cirugía proximal incluye la resección subpericóndrica de la porción anterior y lateral del cartílago cricoides, preservando la placa posterior, sitio de entrada de los nervios laríngeos recurrentes, y resecando toda la mucosa enferma dejando el cartílago expuesto, de acuerdo con las técnicas descritas por Pearson y Grillo ${ }^{13,15}$ (Figura 8). La parte anterior de la anastomosis se realiza entre la tráquea y el borde inferior del cartílago tiroides, y la posterior se lleva a cabo ascendiendo un colgajo elaborado a partir de la porción membranosa de la tráquea para cubrir totalmente el cartílago expuesto de la placa posterior del cricoides y suturándolo a la mucosa sana de la laringe. ${ }^{5}$ En los casos en que la lesión se extiende hasta la glotis comprometiendo la comisura posterior, se practica una laringofisura y se amplía la resección en el sentido proximal para incluir toda la mucosa enferma. La reconstrucción se lleva a cabo de la misma forma, ascendiendo el colgajo de tráquea membranosa hasta la glotis ${ }^{14}$ (Figuras 9, 10, 11). En este tipo de reconstrucción puede presentarse edema de la laringe, situación en la que es posible proteger en forma temporal la vía aérea con un tubo o una cánula de traqueostomía de pequeño calibre. Cuando se ha perdido la
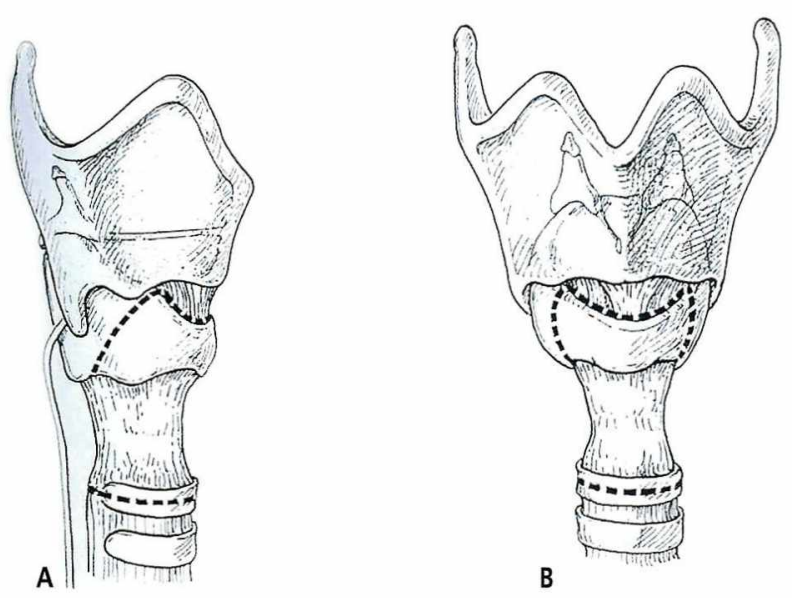

Figura 8. Límites de la resección de una estenosis subglótica con resección de la porción anterior y lateral del cartílago cricoides.

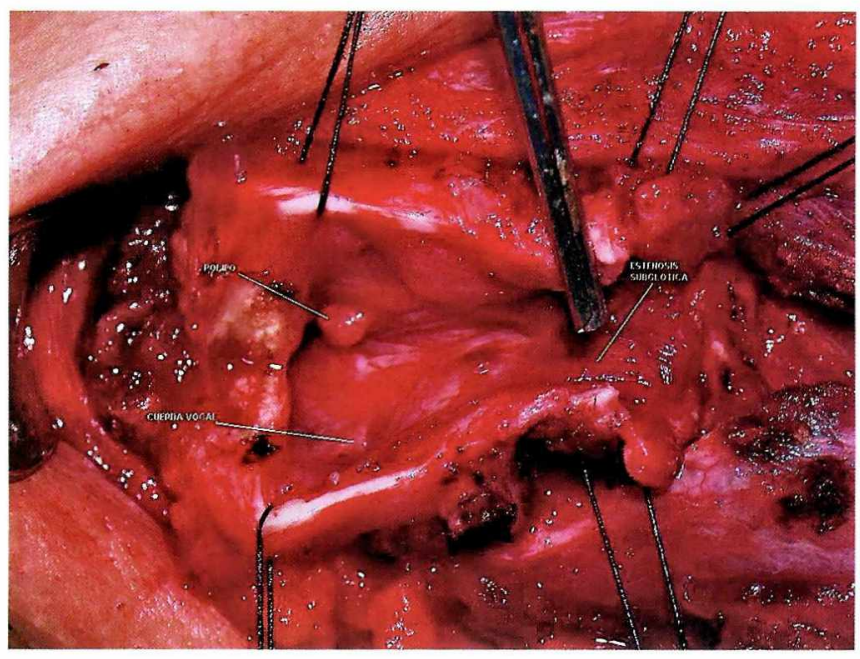

Figura 9. Resección de estenosis subglótica con reconstrucción sincrónica de la laringe. Laringofisura. 


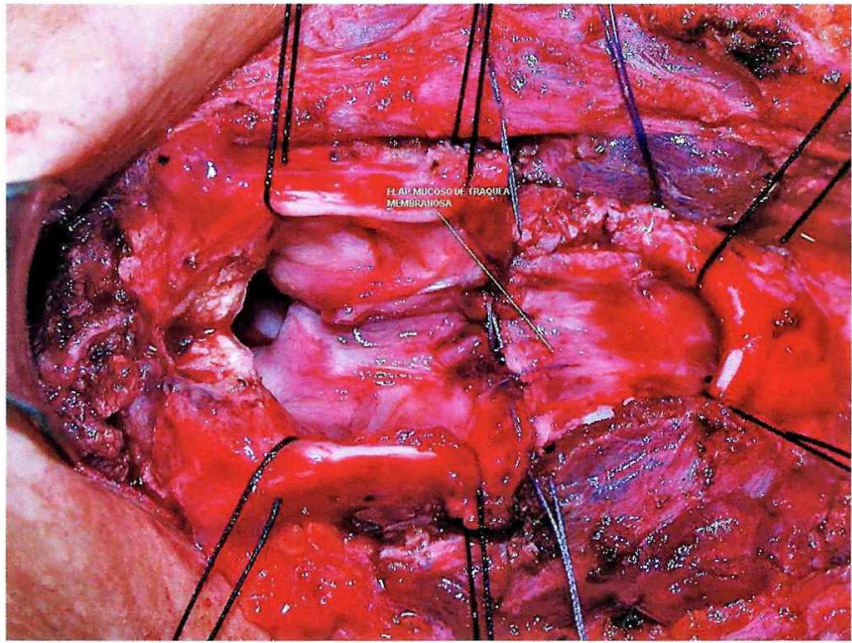

Figura 10. Resección de estenosis subglótica con reconstrucción sincrónica de la laringe. Sutura del colgajo realizado a partir de la tráquea membranosa para remplazar la mucosa fibrótica del espacio subglótico.

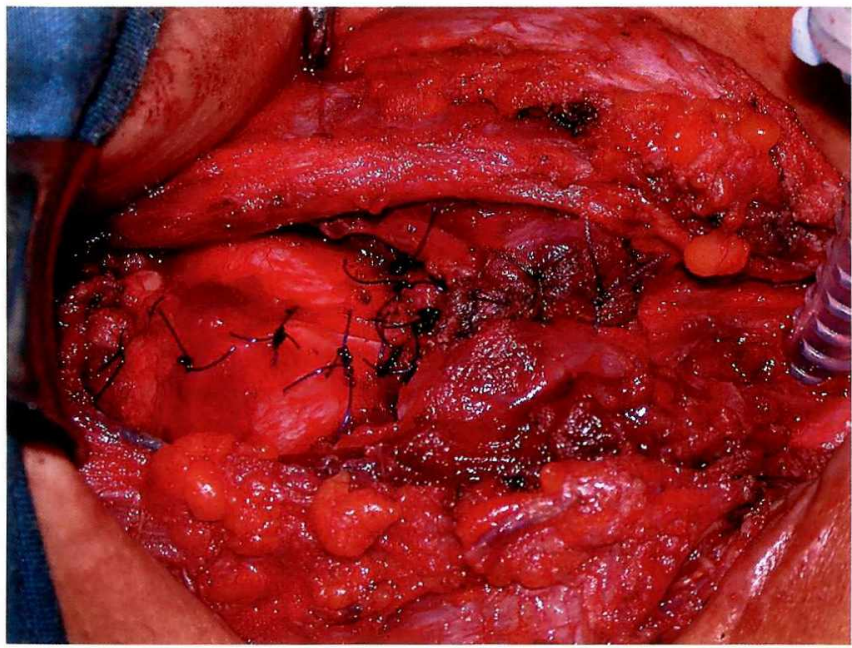

Figura I I. Resección de estenosis subglótica con reconstrucción sincrónica de la laringe. Reconstrucción terminada. Se ha dejado un tubo en $\mathrm{T}$ de Montgomery cuya rama superior ha quedado un centímetro por encima de las cuerdas vocales.

estabilidad del aparato laríngeo, está indicado el soporte interno de la vía aérea con un tubo en $\mathrm{T}$ de Montgomery, cuyo extremo proximal se sitúa cinco milímetros por encima de las cuerdas vocales (Figura 12) y se mantiene durante un tiempo mínimo de seis meses.

\section{Evaluación de los resultados}

Los resultados del procedimiento de resección y reconstrucción fueron evaluados en la consulta externa

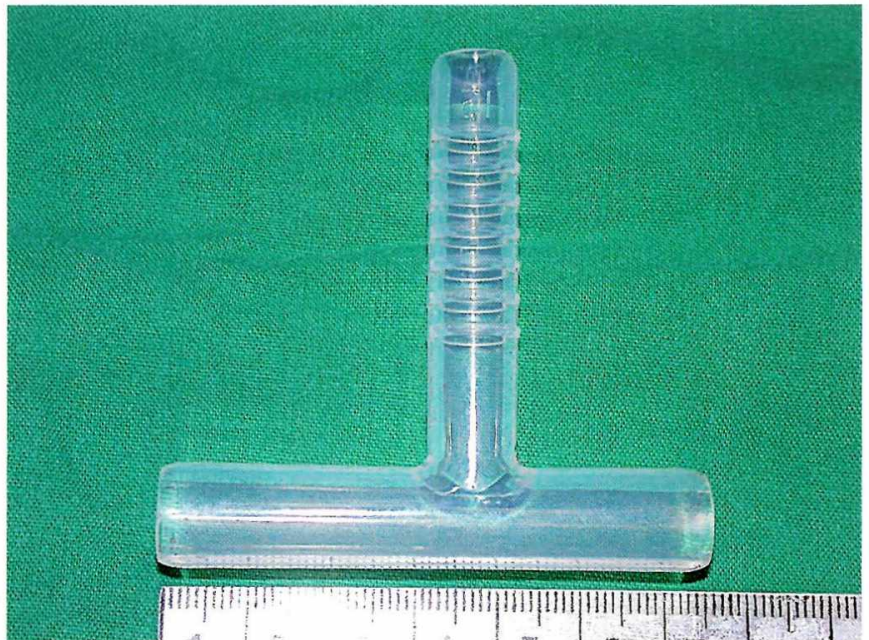

Figura I2. Tubo en T de Mongomery utilizado como molde después de la resección.

y clasificados en cuatro categorías: excelentes, satisfactorios, malos y muertes. Se consideraron excelentes cuando los pacientes han regresado a sus actividades normales y no existe evidencia radiológica o endoscópica de estenosis de la vía aérea; satisfactorios cuando puede realizar sus actividades normales pero refiere disnea con el ejercicio, o bien si detecta parálisis total o parcial de una cuerda vocal o cuando se encuentra en la endoscopia o la radiografía una estenosis de la vía aérea, a pesar de que no se manifieste clínicamente; por último, los resultados se consideraron malos en los casos de estenosis evidente desde el punto de vista clínico o endoscópico que requirió tratamiento con dilataciones o cirugía.

\section{Resultados}

En el período comprendido entre enero de 1996 y abril de 2005 fueron intervenidos 30 pacientes con estenosis traqueales y laringotraqueales. En cuanto al sexo, 16 fueron hombres y 14 mujeres. El rango de edad varió entre 12 y 80 años con un promedio de 44 .

\section{Etiología}

Presentaron estenosis después de intubación de la vía aérea superior, 27 pacientes, 25 por intubación orotraqueal y 2 por traqueostomía. El antecedente 
de intubación se registró en un período que varió entre 30 y 90 días antes de que la estenosis fuera evidente. Las enfermedades por las que se produjo la intubación de la vía aérea se aprecian en la Tabla 1. El tiempo de intubación pudo determinarse sólo en diez pacientes y osciló entre 3 y 45 días. Una paciente presentó estenosis idiopática, uno un seudotumor inflamatorio del cuerpo de la tráquea y en otro se produjo estenosis después de trauma penetrante por arma de fuego con sección parcial del cartílago cricoides.

Tabla I. Etiología de las estenosis laringotraqueales

\begin{tabular}{c|c} 
Postintubación & 27 \\
\hline Idiopática & I \\
\hline Trauma & I \\
\hline Seudotumor inflamatorio & I \\
\hline Total & 30
\end{tabular}

\section{Localización y severidad de la estenosis}

En ocho pacientes la estenosis comprometió la región laringotraqueal, en cuatro de ellos el espacio subglótico y cuatro el glótico en la comisura posterior. Siete fueron secundarias a intubación orotraqueal y una idiopática. En 22 casos se localizó en el cuerpo de la tráquea (Tabla 2).

La longitud del segmento estrecho varió entre dos y seis centímetros con un promedio de $3.5 \mathrm{~cm}$. La severidad del compromiso de la luz osciló entre 70\% y $90 \%$. En dos la lesión consistió en una combinación de estenosis con una zona de traqueomalacia que producía grados variables de obstrucción funcional de la vía aérea. En un caso se debió a intubación prolongada y en otro por una combinación de estenosis por intubación y compresión extrínseca debido a un bocio de gran tamaño.

\section{Cuadro clínico}

Todos los pacientes presentaron cuadro de obstrucción de la vía aérea superior. En aquellos con estenosis postintubación, el intervalo entre la extubación y la aparición de los síntomas pudo
Tabla 2. Localización de la estenosis

\begin{tabular}{c|c}
\hline Cuerpo de la tráquea & 22 \\
\hline Subglótica & 4 \\
\hline Subglótica + comisura glótica & 4 \\
\hline Total & 30
\end{tabular}

establecerse en diez pacientes y varió entre 30 y 90 días. Las causas de la intubación aparecen en la Tabla 3. No se observó ninguna relación entre el desarrollo de estenosis y la duración de la intubación. Los síntomas consistieron en disnea de esfuerzo y estridor laríngeo en todos los enfermos. Dieciocho desarrollaron obstrucción aguda de la vía aérea que requirió intervención inmediata para salvar la vida. Esta situación fue manejada con traqueostomía en 16, doce de las cuales fueron realizadas en otra institución. Dos con obstrucción aguda fueron tratados al principio con dilataciones. Doce tenían cánula de traqueostomía cuando consultaron a nuestro hospital.

\begin{tabular}{c|c}
\hline \multicolumn{2}{|c|}{ Tabla 3. Causas de intubación prolongada } \\
\hline Revascularización miocárdica & 2 \\
\hline Intoxicación por organofosforados & 2 \\
\hline Trauma craneoencefálico & 4 \\
\hline Trauma abdominal cerrado & 3 \\
\hline Neumonía & 6 \\
\hline Pancreatitis & 2 \\
\hline Trauma torácico por arma de fuego & 2 \\
\hline Guillain Barré & 1 \\
\hline Peritonitis & 3 \\
\hline No determinadas & 2 \\
\hline Total & 27 \\
\hline
\end{tabular}

Tres pacientes habían sido sometidos a diferentes procedimientos de resección y reconstrucción en otras instituciones. En dos se practicaron cuatro resecciones del segmento estrecho con anastomosis terminoterminal.En un paciente de 12 años con estenosis subglótica se llevaron a cabo varias cirugías para resección de granulomas, múltiples 
dilataciones con láser y un procedimiento de laringoplastia. Una paciente con una estenosis del cuerpo de la tráquea fue sometida en nuestra institución a dilatación con reaparición temprana de la obstrucción.

\section{Evaluación diagnóstica}

En todos los pacientes se practicaron los siguientes estudios para establecer el diagnóstico y evaluar la localización y severidad de la estenosis:

1. TAC de laringe y tráquea. En nuestro servicio se solicitó uno helicoidal con cortes cada 1 o $2 \mathrm{~mm}$ a nivel de la laringe y reconstrucción en varios planos en todos los pacientes, lo cual permitió establecer de manera muy precisa la localización, severidad y longitud de la estenosis. Los cortes finos evalúan con exactitud los compartimientos laríngeos y el espacio subglótico (Figuras 13, 14, 15).

2. Examen endoscópico de la vía aérea. Todos los pacientes fueron sometidos a fibrobroncoscopia, que confirmó el diagnóstico, la severidad de la estrechez y facilitó el diagnóstico diferencial entre las estenosis de la vía aérea. En el paciente con una lesión tumoral se tomó biopsia para diagnóstico histológico.

3. Resonancia nuclear magnética. Tres enfermos la traían en el momento en que fueron evaluados por primera vez en nuestro servicio. Este estudio no contribuyó con información adicional a la proporcionada por TAC.

4. Tomografía lineal. Dos pacientes fueron evaluados en otras instituciones con esta técnica.

5. Curva flujo-volumen: 14 pacientes que presentaban cuadro clínico de obstrucción de la vía aérea revelaron un patrón de obstrucción fija.

6. Gases arteriales. Todos se evaluaron: en aquellos con obstrucción aguda se encontró hipoxemia leve a severa en diez y retención de $\mathrm{CO} 2$ en cinco.

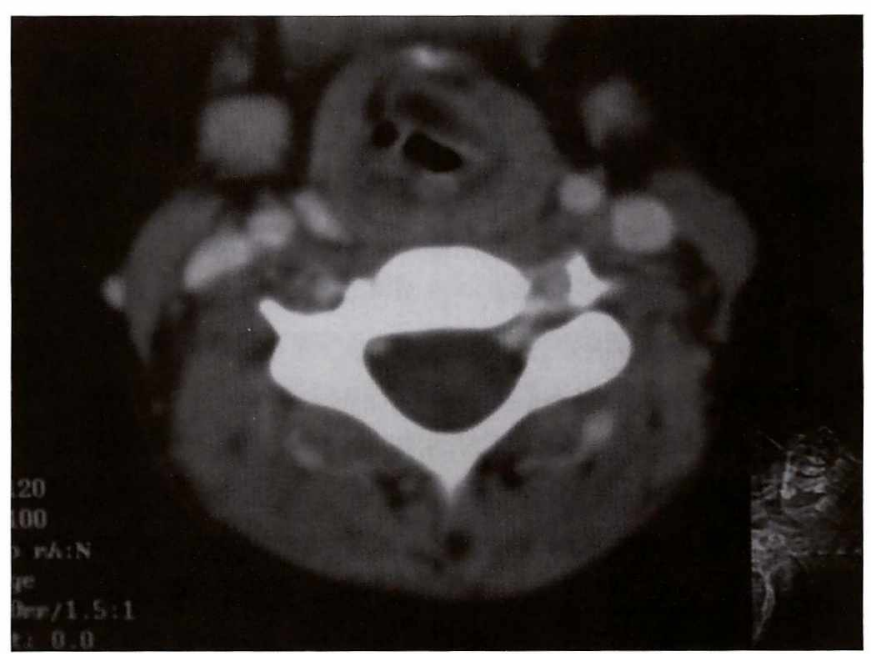

Figura I3. TAC de laringe y tráquea que muestra una estenosis subglótica.

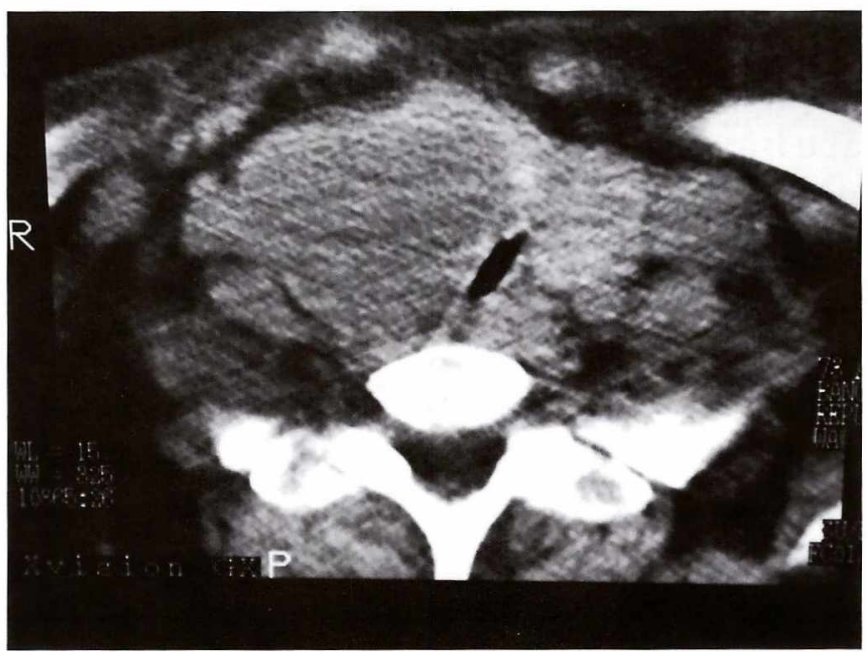

Figura 14. TAC del tórax que muestra una estenosis de la tráquea producida por compresión extrínseca por un bocio.

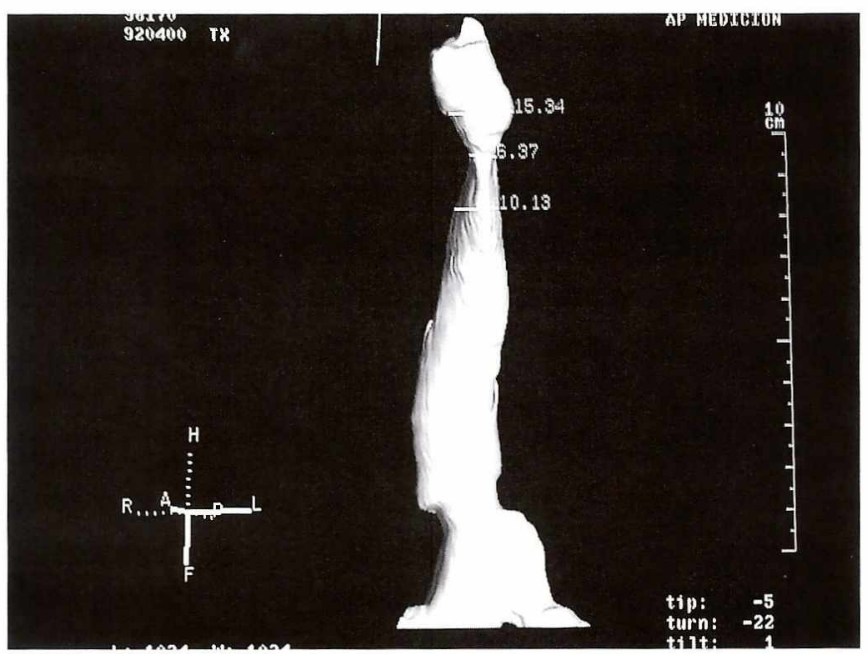

Figura 15. Reconstrucción tridimensional de una tomografía de la tráquea que muestra una estenosis traqueal. 


\section{Tratamiento quirúrgico}

Todos fueron sometidos a procedimientos de resección y reconstrucción mediante anastomosis terminoterminal de la vía aérea de acuerdo con las técnicas descritas (Tabla 4). En 26 se hizo abordaje cervical y cuatro requirieron uno combinado cervical y esternal. En cuatro con estenosis subglóticas se realizaron resecciones de la placa anterior del cartílago cricoides y de la mucosa enferma que se encontraba recubriendo la placa posterior, hasta exponer el cartílago. El defecto mucoso que resultó se cubrió con un colgajo de tráquea membranosa y se practicó una anastomosis entre el cartílago tiroides y el segmento distal de tráquea, de acuerdo con la técnica descrita por Grillo. En un paciente se dejó una cánula de traqueostomía de pequeño calibre para mantener la vía aérea, debido al edema en el área de reconstrucción. En otro se dejó un tubo en T de silástico como molde, el cual se mantuvo durante siete meses. Los demás fueron extubados al terminar el procedimiento.

Cuatro enfermos que presentaron lesiones que comprometían la glotis requirieron una reconstrucción compleja que consistió en la práctica de una laringofisura, además de la resección de toda la porción anterior del cartílago cricoides, de acuerdo con la técnica descrita por Maddaus y cols.${ }^{14} \mathrm{La}$ apertura de la laringe permitió realizar la resección amplia de todo el tejido fibroso que comprometía el espacio subglótico y la comisura posterior, y remplazar el defecto con un colgajo de tráquea membranosa del segmento distal. En dos de estos pacientes se dejó un tubo en $\mathrm{T}$ de Montgomery durante seis meses y en otro se colocó una cánula de traqueostomía $\mathrm{N}^{\circ} 6$ que se dejó por ocho días.

Veintidós casos con estenosis del cuerpo de la tráquea fueron tratados con resección y anastomosis primaria de segmentos de tráquea cuya longitud varió entre tres y seis centímetros. Quince pacientes con resecciones mayores de tres centímetros requirieron maniobras de liberación laríngea, suprahioideas en diez e infrahioideas

Tabla 4. Procedimientos quirúrgicos

Abordaje cervical

Abordaje cervical y transesternal

Resección segmentaria y anastomosis terminoterminal

Resección parcial del cricoides y anastomosis terminoterminal

Laringofisura + resección parcial de cricoides + anastomosis TT

en cinco. Tres con estenosis mayores de cinco centímetros requirieron esternotomía media para movilización y ascenso del hilio pulmonar derecho mediante las maniobras arriba descritas.

En una paciente con estenosis traqueal post intubación asociada con una zona amplia de traqueomalacia causada por compresión por un bocio, el procedimiento de resección y reconstrucción se combinó con una tiroidectomía total. Después del procedimiento de resección y reconstrucción, cinco casos requirieron intervenciones menores para extirpar granulomas en la zona de la anastomosis. Solo una presentó una nueva estenosis después de haberle realizado resección de una subglótica con reconstrucción laringotraqueal. Ella fue reintervenida seis meses después del procedimiento inicial. La operación consistió en una resección de la nueva estenosis que comprometía hasta la comisura posterior de la glotis, para lo cual se hizo necesaria una laringofisura y reconstrucción laringotraqueal. Además, se le hizo una lateralización de la cuerda vocal derecha. Se le dejó un tubo en T, el cual permanece en su lugar hasta la fecha de corte de este estudio.

\section{Cuidados postoperatorios}

Después de la cirugía, nueve pacientes fueron trasladados a la sala de recuperación y luego al piso. Veintiuno requirieron traslado a la UCI para ventilación mecánica (4) o para monitoreo (17). Los que necesitaron ventilación mecánica se extubaron en las 48 horas siguientes. El tiempo de hospitalización en cuidados intensivos varió entre uno y tres días. 
El manejo postoperatorio consistió en micronebulizaciones con esteroides durante las primeras 48 horas para disminuir el edema de la vía aérea, incentivo respiratorio y antibióticos por vía sistémica durante siete a diez días, en ocho pacientes en quienes se diagnosticó infección de la vía aérea antes de cirugía o presentaban secreciones purulentas. Los puntos de flexión del cuello se retiraron al séptimo día y todos recibieron terapia física con el fin de aliviar el espasmo de los músculos ocasionado por la flexión prolongada del cuello. El tiempo total de hospitalización varió entre ocho y veinte días con un promedio de nueve.

\section{Mortalidad}

En esta serie se presentaron dos casos de mortalidad. Ambos fueron debidos a fístulas traqueoinnominadas con hemorragia masiva. El primero cursó con hemoptisis premonitoria, razón por la cual fue reintervenido, sin encontrarse la causa de la hemorragia. Al día siguiente se produjo un sangrado masivo a causa del cual falleció. Había sido sometido a una segunda resección de una estenosis subglótica y de un segmento de seis centímetros del cuerpo de la tráquea por vía cervical y esternal, y requirió maniobras extensas de liberación de la laringe y la tráquea en el mediastino. En el momento de la segunda intervención se encontró que la traqueostomía previa había sido realizada sobre el sexto anillo de la tráquea, en estrecho contacto con la arteria innominada.

El segundo paciente presentó una hemorragia fatal por una fístula tráqueo innominada, en el sitio del estoma de la cánula de traqueostomía. Fue sometido a una segunda reintervención después de dos cirugías previas de resección y reconstrucción practicadas en otra institución, y requirió resección extensa de una estenosis subglótica y una zona de traqueomalacia de cinco centímetros. En ambos casos el tronco de la arteria innominada se aisló de la anastomosis mediante la interposición de un colgajo pediculado de músculos pretiroideos.

\section{Complicaciones postoperatorias}

Se presentaron siete complicaciones en 30 procedimientos de resección y reconstrucción (Tabla 5). Uno desarrolló neumotórax en el postoperatorio inmediato, debido a una apertura inadvertida de la pleura durante la disección de la tráquea en el mediastino y fue tratado con un tubo de toracostomía. Otro no pudo ser extubado en la sala de cirugía porque el tubo endotraqueal quedó atrapado por una de las suturas de la tráquea. La reconstrucción tuvo que ser revisada y hecha de nuevo. Dos presentaron atelectasia de un lóbulo y un pulmón y fueron

Tabla 5. Complicaciones postoperatorias.

\begin{tabular}{l|l}
\hline Atelectasias & 2 \\
\hline Neumotórax & I \\
\hline Traqueitis + neumonía nosocomial & I \\
\hline Fistula traqueoinnominada & 2 \\
\hline Sutura inadvertida del tubo endotraqueal & I \\
\hline Total & 7
\end{tabular}

tratados con reclutamiento pulmonar con presión positiva. Una desarrolló neumonía nosocomial, con secreción purulenta en la tráquea por Pseudomona aeruginosa. En dos aparecieron fístulas traqueoinnominadas con hemorragia masiva a causa de las cuales fallecieron. Cuatro pacientes a quienes se les practicaron maniobras de liberación de la laringe mostraron alteraciones transitorias en la voz o disfagia (una liberación suprahioidea y tres tirohioideas), que mejoraron con rehabilitación.

\section{Seguimiento y resultados funcionales}

El seguimiento se hizo en la consulta externa y por llamada telefónica a quienes no habían asistido a control en más de un año. En 26 pacientes se obtuvieron resultados excelentes consistentes en el alivio completo de la obstrucción con un calibre normal de la vía aérea y recuperación de la voz normal. En una los resultados fueron clasificados como buenos. Se trataba de una estenosis compleja que comprometía la glotis y el tono de la voz que se obtuvo después 
del procedimiento fue ligeramente menor al usual de la paciente.

En un caso los resultados fueron malos, debido a la recurrencia de la obstrucción después de resección y reconstrucción laringo-traqueal por una estenosis subglótica. Se realizó una nueva cirugía de resección y reconstrucción encontrándose una estenosis subglótica que se extendía hasta la glotis y parálisis de una cuerda vocal. Los resultados fueron clasificados como satisfactorios.

\section{Discusión}

Las lesiones que producen estenosis de la vía aérea superior son particularmente complejas por varias razones: el riesgo de producir una obstrucción aguda que pone en peligro la vida del paciente, el compromiso de la voz y la deglución dependiendo del sitio en el que se localizan y el compromiso de órganos y estructuras vecinas como el nervio recurrente laríngeo, el esófago y los grandes vasos del cuello y del mediastino. Además la selección de los procedimientos quirúrgicos para la resección y posterior reconstrucción de la vía aérea debe ser el resultado del análisis de las imágenes diagnósticas y del conocimiento profundo de las técnicas quirúrgicas, sus indicaciones y aplicación en el contexto específico de cada situación. Las consideraciones anteriores determinan que el abordaje debe hacerse por un grupo interdisciplinario experto que involucra las siguientes especialidades: imágenes diagnósticas, neumología, cirugía del tórax, otorrinolaringología, anestesia y cuidados intensivos.

Las lesiones postintubación todavía son la causa más frecuente de estenosis benigna de la vía aérea superior. Pueden ser producidas después de una intubación translaríngea o de una traqueostomía. La primera puede causar lesión a la altura de la glotis, la región subglótica o la tráquea. Por lo regular se presenta después de períodos variables de intubación oro o nasotraqueal en pacientes que han requerido ventilación mecánica en la UCI (Figura 16). El compromiso laríngeo se ve con mayor frecuencia en

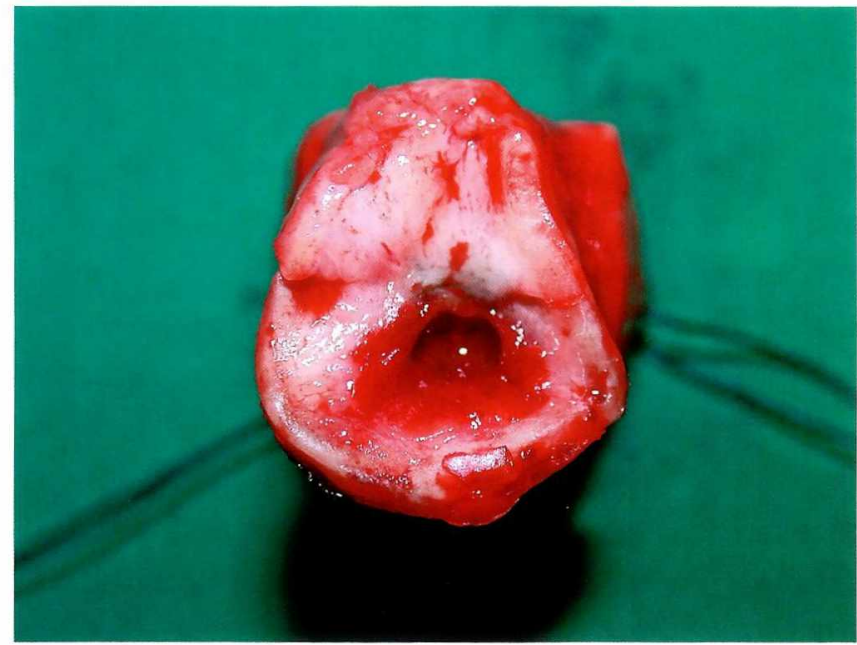

Figura I 6. Estenosis post intubación.Vista frontal del segmento estrecho resecado. Nótese el proceso cicatricial severo.

la zona posterior entre los aritenoides con limitación de la abducción de las cuerdas vocales o en el espacio subglótico originando una estenosis concéntrica, por lo general severa. Con la traqueostomía, las estenosis pueden producirse por lesión a la altura del traqueostoma o por isquemia por compresión del balón inflable. La erosión de toda la pared de la traquea por este último puede traer como resultado una fístula traqueoinnominada o una traqueoesofágica.

Las lesiones producidas por el balón de los tubos endotraqueales y cánulas de traqueostomía fueron descritas por Pearson y colaboradores y Grillo y colaboradores en los años sesenta, cuando eran fabricados con balones de bajo volumen y alta presión ${ }^{3,5}$. Se debían a isquemia de la mucosa por la acción compresiva del balón sobre la pared de la tráquea.

Su incidencia disminuyó en forma significativa con la incorporación de los balones de alto volumen y baja presión en los tubos y las cánulas de traqueostomía. No obstante, pueden presentarse cuando no se controla la presión del balón $(<20$ $\mathrm{mm} \mathrm{Hg}$ ) o cuando no se desinfla en forma intermitente. Por lo general se localizan en el cuerpo de la tráquea, no revisten mayor complejidad y su tratamiento consiste en la resección del segmento comprometido y la reconstrucción posterior con anastomosis terminoterminal. 
Las estenosis que comprometen la traquea y la laringe son lesiones muy complejas, porque además de obstruir la luz, comprometen de manera temporal o definitiva la función de la laringe. Se observan con mayor frecuencia por intubación translaríngea, aunque de manera ocasional puede aparecer después de traqueostomía, cuando ésta se lleva a cabo a través del primer anillo de la tráquea o de una cricotiroidotomía. Su manejo requiere procedimientos quirúrgicos complejos de resección y reconstrucción de la laringe y la tráquea, como los descritos por Pearson, Grillo y Coureaud y realizados en este estudio. ${ }^{11,13,15 .}$ La mayor severidad de las lesiones por los tubos oro y nasotraqueales podría constituir un argumento a favor de la realización temprana de traqueostomía en los pacientes que requieren ventilación mecánica prolongada.

El tiempo de duración de la intubación es variable y no guarda relación con la aparición y la severidad de la estenosis, como ha sido demostrado en la literatura y confirmado con los hallazgos de nuestro estudio. El intervalo entre la extubación y la aparición de síntomas de obstrucción de la vía aérea también es variable.

Las lesiones secundarias a intubación de la tráquea pueden ser variadas: las más comunes son los granulomas que pueden resecarse por vía endoscópica; otras son las membranas o diafragmas que son muy cortos pero que pueden producir estenosis severas; en estas la pared de la tráquea se encuentra intacta, por lo que pueden resecarse con dilataciones, electrocoagulación o láser. Las más severas son las estenosis fibrosas, en las que ya existe un proceso inflamatorio y cicatricial que compromete todo el espesor de la pared, con pérdida del cartílago, que hace imposible cualquier tratamiento local.

En ocasiones se observan estenosis que se clasifican como idiopáticas porque no tienen causa conocida. Tienden a ser concéntricas y se localizan de manera típica en la parte inferior de la laringe y la superior de la tráquea. Se caracterizan en la histología por la presencia de fibrosis densa de la pared de la tráquea y desde el punto de vista clínico por la ausencia de antecedentes y la irreversibilidad de la estenosis. ${ }^{16}$ La paciente descrita en nuestra serie presentaba una severa que comprometía la glotis, el espacio subglótico y la porción superior de la tráquea. Requirió un procedimiento quirúrgico complejo de resección y reconstrucción.

La obstrucción ocasionada por tumores o trauma de la vía aérea son menos frecuentes. El trauma por lo general causa afecciones agudas que requieren tratamiento inmediato y sólo en raras ocasiones se manifiestan de manera tardía con un cuadro de obstrucción de la vía aérea superior. En nuestra serie se presentó un paciente con herida penetrante por proyectil de arma de fuego que no tenía evidencia de compromiso de la vía aérea al ingreso y pocos días después desarrolló obstrucción con disnea y estridor. En la exploración quirúrgica se halló una sección parcial de la porción lateral del cartílago cricoides con intrusión de un fragmento de cartílago en la luz de la vía aérea.

Varios métodos y procedimientos de imágenes diagnósticas se han utilizado para evaluar las estenosis laringotraqueales, entre ellos, endoscopia, radiografía simple del cuello con megavoltaje, tomografía lineal, xerografía, TAC y resonancia magnética. Consideramos que el examen endoscópico es fundamental para diagnosticar el tipo y la severidad de la lesión, así como su longitud. En presencia de obstrucción severa de la luz es preferible utilizar el broncoscopio rígido porque permite mantener la ventilación del paciente y dilatar la vía aérea, usando en forma progresiva broncoscopios de calibres cada vez mayores hasta obtener una luz que haga posible mantener temporalmente la vía aérea mientras se realiza el tratamiento definitivo de resección y reconstrucción. Durante el procedimiento pueden resecarse lesiones como los granulomas y membranas que estén causando obstrucción. La TAC realizada con técnica helicoidal y con reconstrucción multiplanar se ha convertido en el método preferido para evaluar las estenosis laringotraqueales y proporciona información de enorme valor. Cuando se hacen cortes cada uno o dos milímetros se puede hacer una evaluación muy completa de la laringe y el espacio subglótico. Las reconstrucciones en múltiples planos 
permiten una apreciación bastante exacta de la longitud de la estrechez. La resonancia magnética no brinda información adicional con respecto al TAC.

Un aspecto de enorme importancia es el manejo de la obstrucción aguda de la vía aérea, puesto que de él depende en gran medida la posibilidad de realizar una cirugía reconstructiva exitosa. En lo posible debe hacerlo un cirujano experto, con broncoscopia rígida y dilatación de la estrechez en salas de cirugía y en un centro de atención de alto nivel de complejidad, evitando la traqueostomía que implica sacrificar uno o dos centímetros de tráquea sana que pueden ser críticos en una reconstrucción posterior. No obstante, en nuestro medio con frecuencia estos recursos no se encuentran disponibles, por lo que es necesario recurrir a la traqueostomía de urgencia. En este caso se debe emplear una cánula de pequeño calibre y realizar la incisión en la tráquea directamente en el sitio de la estrechez, con el fin de preservar la mayor longitud posible de vía aérea sana.

Se han utilizado varias modalidades de tratamiento conservador en el manejo de las lesiones post intubación como dilataciones repetidas, aplicación de esteroides tópicos y sistémicos, criocirugía, fulguración con electrocauterio, láser y el uso transitorio o permanente de diversos tipos de férulas (stents). Todos estos tratamientos tienen la ventaja potencial de una incidencia muy baja de complicaciones y han sido reportados como exitosos en casos muy seleccionados. ${ }^{17}$ En general, el tratamiento conservador no ofrece posibilidades de éxito duradero en estos enfermos cuyas dos únicas opciones son la intubación permanente de la vía aérea y la reconstrucción quirúrgica. De acuerdo con Grillo, quienes han tenido tubos o férulas por meses, incluso años, experimentan el cierre agudo de la vía aérea a los 40 o 50 minutos después de la remoción de una cánula de traqueostomía o a los pocos días o semanas después de la remoción del tubo en T. ${ }^{17}$ En la medida en que las técnicas de reconstrucción quirúrgica se han perfeccionado y la experiencia con ellas es mayor, estamos cada vez más convencidos de que la resección y la reconstrucción temprana se encuentran ampliamente justificadas y que el tratamiento conservador no es alternativa apropiada.

\section{Referencias}

1. Hopkinson DN, Keshavjee S: Inflammatory conditions. En: Pearson FG, Cooper JD, Deslauriers J, editors. Thoracic Surgery. 2ND. ed. Churchill Livingstone; 2002. p 325.

2. Grillo HC, Donahue DM. Postintubation tracheal stenosis. Chest Surg Clin N Am. 1996 Nov;6(4):725-31.

3. Pearson FG, Goldberg M, da Silva AJ. A prospective study of tracheal injury complicating tracheostomy with a cuffed tube. Ann Otol Rhinol Laryngol. 1968 Oct;77(5):867-82.

4. Pearson FG, Andrews MJ. Detection and management of tracheal stenosis following cuffed tube tracheostomy. Ann Thorac Surg. 1971 Oct;12(4):359-74.

5. Grillo HC. Surgery of the trachea. En: Ravitch MM, editors. Current problems in Surgery. Chicago: Year Book Medical Publishers, 1970.

6. Dedo HH, Fishman NH. Laryngeal release and sleeve resection for tracheal stenosis. Ann Otol Rhinol Laryngol. 1969 Apr;78(2):285-96.

7. Montgomery WW. Suprahyoid release for tracheal anastomosis. Arch Otolaryngol. 1974 Apr;99(4):255-60.

8. Ogura JH, Powers WE. Functional restitution of traumatic stenosis of the larynx and pharynx. Laryngoscope. 1964 aug;74:1081-110.

9. Pearson FG, Cooper JD, Nelems JM, Van Nostrand AW. Primary tracheal anastomosis after resection of the cricoid cartilage with preservation of recurrent laryngeal nerves. J Thorac Cardiovasc Surg. 1975 Nov;70(5):806-16.

10. Monnier P, Savary M, Chapuis G. Partial cricoid resection with primary tracheal anastomosis for subglottic stenosis in infants and children. Laryngoscope. 1993 Nov;103(11 Pt 1):1273-83.

11. Couraud L, Hafez A. Acquired and non-neoplastic subglotic stenosis. En: Grillo HC, Eschapasse H, editors. International trends in general thoracic surgery: major challenges. Vol 2. Philadelphia : WB Saunders; 1987. p. 91-110.

12. Grillo HC, Mathisen DJ, Wain JC. Laryngotracheal resection and reconstruction for subglottic stenosis. Ann Thorac Surg. 1992 Jan;53(1):54-63.

13. Grillo HC. Primary reconstruction of airway after resection of subglottic laryngeal and upper tracheal stenosis. Ann Thorac Surg. 1982 Jan;33(1):3-18.

14. Maddaus MA, Toth JL, Gullane PJ, Pearson FG. Subglottic tracheal resection and synchronous laryngeal reconstruction. J Thorac Cardiovasc Surg. 1992 Nov;104(5):1443-50.

15. Pearson FG: Technique and management of subglotic stenosis. Chest Surg Clin N Am. 1996 Nov;6(4):68392.

16. Grillo HC. Management of idiopathic tracheal stenosis. Chest Surg Clin N Am. 1996 Nov;6(4):811-8.

17. Grillo HC. Postintubation estenosis. En: Grilo HC, editores. Surgery of the trachea and bronchi. London : BC Decker Inc. Hamilton; 2004. 